\section{Road and Rail Transport in India}

An article by C. N. R. Rau in Current Science of March on "The Co-ordination of Road and Rail Transport" reviews recent experience of transport in the Empire both before and during the War, with special reference to India, and endeavours to indicate basic principles of service which should determine both the choice and organization of transport. Discussing the handicaps under which rail transport generally labours, Mr. Rau considers that the plea for a 'square deal' for the railways is well founded. $\mathrm{He}$ suggests that investigation is still required to determine how far co-ordination of inland transport can meet the recognized ideals of service, whether in the transport of goods or passengers, or from the point of view of operating efficiency and safety, and indicates that both road and railway transport services might explore the field of public relations much more thoroughly. Emphasizing the importance of coordination, once it is clear as to the types of traffic best suited for one form or other of transport, he suggests that legislative or Government control, without nationalization, could with a judicious road policy, so shape the transport system of India that the two methods would work as complementary units, each performing the work best suited to itself and rendering the best service to the community.

The value of agreements between the two systems, of mutual recognition, and the organization of road transport with reference to railway stations, for example, by the use of railway stations as bus termini, the interavailability of tickets, publicity of one service on the other, the application of "undue preference" and "common, carrier" clauses to both systems, are among concrete suggestions advanced for the promotion of efficient transport in India, as well as consideration of the establishment of an organization under joint auspices, entrusted with the task of collecting, analysing and collating all relevant inform. ation in regard to problems of common interest. Road operating statistics should be published on the same lines as railway statistics, and the State should insist on the organization of road haulage on the lines adopted by the railways, so that the two systems can negotiate on an equal footing and share the benefits of any co-ordination schemes.

\section{Diesel-Electric Tube Locomotive}

The London Passenger Transport Board is utilizing parts of old railway coaches from the "Central Line" of the underground system for building at its Acton works Diesel locomotives for hauling ballast and. maintenance trains, or for emergency use in the 'tubes'. These duties are at present performed by tank-type steam locomotives. It is arranged to collect current from the live 600 -volt track rail, or be propelled by its self-contained generating set as circumstances may require, and it is capable of hauling a 600-ton train on the level or one of 300 tons up a 1 in 34 gradient. The length of the vehicle is $57 \mathrm{ft}$., its width $8 \mathrm{ft} .2 \mathrm{in}$., its height $9 \mathrm{ft} .5 \mathrm{in}$., and the tare weight in running order is 62 tons
12 cwt. According to the Electrical Review of May 16, only the oil engine and generator with some switchgear had to be purchased in fabricating the train. The passenger compartments of two old driving cars were cut off, leaving the equipment compartments with motors and driver's cabs; these were joined together. The locomotive can be controlled from either end. Its engine is of the Petter 'superscavenge' airless injection, two-stroke cycle, cold starting type. The six cylinders develop 506 b.h.p. at 675 r.p.m. The engine is started by means of compressed air at $350 \mathrm{lb}$. per sq. in. The generator, which was made by the Brush Electrical Engineering Co. Ltd., is a level-compounded shunt machine with a continuous rating of $750 \mathrm{amp}$. at $450 \mathrm{v}$. The traction equipment consists of two series-parallel sets with automatic relay controlling notching.

\section{Control of Pig Raising}

C. P. McMrezan has furnished what, in view of the present food situation, should prove a valuable analysis of the growth and development of the pig with special reference to carcass quality characters. The five parts (J. Agri. Sci., 30, 1940; 31, 1941) with their appendixes have been conveniently issued together. The aim of the work is to provide a base from which to control the raising of pigs as meatproducing animals. It is, therefore, particularly concerned with the effects of nutrition upon not only the growth and size of the pig as a whole but also upon the quality of the meat produced. The author admits that the term 'meat quality' is not possible of exact definition in a form capable of universal application, but some approximation can be made thereto. Of course it will vary with the use to which the meat is to be put and also with the local tastes and requirements. The bulk of the memoir is naturally concerned with the statement of a number of experiments and an analysis of their results, but general ideas are not overlooked and the work concludes with a review of the main principles that emerge and their wider application even to human beings.

\section{British Natural History}

Despite the increasing difficulties and demands upon the spare-time, amateur as well as professional, natural history continues in Great Britain. The summer Bulletin of the British Empire Naturalists' Association records the continuance of branch activities at Bournemouth, Merseyside, Derbyshire, North Cotswold, London, Manchester and Lancaster ; in fact only two branches have closed since the outbreak of war. 1941 field records include the first definite nesting of the fulmar on St. Bee's Cliff, Cumberland; Bewick's swans and a green sandpiper on spring passage in Lancashire; a fire-crest at Stanmore, Middlesex, on April 6 ; siskins at Farnham, Surrey, April 30, and a bird migration survey over twelve counties. The 1940 edition of the Burtonon-Trent Natural History and Archæological Society records has appeared and directs attention to the opportunity for studying the changes the war-time felling of woods will have upon bird, plant and insect life. 
The Merseyside Naturalists' Association is shortly publishing its new book on the birds of west Lancashire and west Cheshire ; the Blackburn Naturalists' Field Club reported a record attendance, averaging two hundred, at its indoor evening meetings last winter, and the recent summer meeting of the NorthEast Lancashire Naturalists' Union at Darwen was very well attended. The Thunder Census Organization is carrying on its work and has just issued its fifth annual report from Langley Terrace, Oakes, Huddersfield, and particulars of trees struck by lightning are being collected. The Liverpool Botanical Society is continuing its field work for the publication of its "Flora of South Lancashire" and the North of England Zoological Society, Chester, has made its monthly journal the organ for reporting the activities of other zoological collections since the Animal and Zoo Magazine of the London Society suspended publication, and London, Dudley and Maidstone Zoos contribute to the June issue.

\section{Medicine in Saint-Simon's "Memoires"}

IN a recent paper on this subject (Proc. Roy. Soc. Med., 34, Sect. Hist. Med. 31 ; 1941) Dr. J. D. Rolleston claims that this work, which covered twenty-one years of the reign of Louis XIV and eight years of the Regency, contained many passages of medical interest, though they had received little attention from medical historians. They could be classified under the headings of prevalent diseases, portraits of contemporary doctors and miscellaneous topics. Small-pox was by far the most frequent of all the diseases mentioned by Saint-Simon, and its prevalence among royal personages and courtiers was a striking proof of the efficacy of Jenner's discovery, as since that time the disease was almost unknown among the upper classes in whom conscientious objectors were rare. Among chronic infections described in the "Mémoires" syphilis undoubtedly held the first place and claimed several courtiers of both sexes among its victims. Many cases of lung disease, probably of a tuberculous nature, are also mentioned. As might be expected owing to their indulgence in highly nitrogenous diet, large consumption of alcohol and lack of exercise, a great number of courtiers as well as Louis XIV suffered from gout. Several examples of nervous and mental diseases as well as alcoholism and cancer are also alluded to by Saint-Simon. Of the thirteen surgical operations mentioned five were for stone in the bladder and four for fistula in ano, a complaint which, after the operation on Louis XIV, became as fashionable as appendicitis did more than two centuries later after the operation on Edward VII.

The "Mémoires" also contain brief indications of three diseases - achondroplasia, spondylitis deformans and hæmophilia-long before they were described in scientific medicine. As regards his attitude towards the medical profession, Saint-Simon, like many other distinguished laymen before and since his time, did not appear to have a liking for doctors, as is shown by the frequency with which he declared that they had not understood the nature of the disease which they were treating. On the other hand, he was unsparing in his eulogies of individual doctors, such as Fagon, Louis XIV's physician, Mareschal, his surgeon, and Hyghens, the king of Spain's physician who attended Saint-Simon during his attack of smallpox. The miscellaneous topics of medical interest mentioned in the "Mémoires" include longevity, sexology, spas, poisoning, post mortem examinations and the illnesses of Louis XIV.

\section{History of Endocrinology}

IN a recent paper on this subject read before the Section of the History of Medicine of the Royal Society of Medicine (Proc. Roy. Soc. Med., 34, 303 ; 1941) Dr. A. P. Cawadias said that three periods could be distinguished in the historical development of endocrinology. The first was the descriptive period, the second was one of analytic endocrinology and the third or contemporary period was that of synthetic endocrinology. The first description of endocrine diseases was given long before there was any accurate knowledge of endocrine physiology, being found in the writings of Hippocrates, who studied hypo-orchidism and climacteric hypoovarism. Only after some advance was made in the knowledge of glandular physiology, however, were endocrine diseases introduced into nosography. The earliest of these was hypothyroidism, studied by $\mathrm{T}$. Curling in 1850 and later by C. H. Fagge in 1871 and Sir William Gull in 1873. Hypo-adrenalism was described by Addison in 1855, when endocrine nosography first made a real start. A notable advance in the history of endocrine diseases was made by the introduction of endocrinotherapy. This began with Brown-Séquard in 1889 , reached a notable peak with the introduction of thyroid organotherapy by G. R. Murray in 1890, and developed intensively in recent years, outstanding events being the introduction of insulinotherapy by Banting in 1921, of the various sex hormones and of cortin.

\section{The Wyperfeld (Mallee) National Park}

The Mallee National Park in Victoria, known as "Wyperfeld", an account of which appeared in NATuRE of August 12, 1939, p. 272, has received a substantial addition of 51,840 acres, owing to the far-sighted action of the acting premier of Victoria, $\mathrm{Mr}$. Lind. This makes a total area of 138,700 acres. The land added, known locally as the "Desert", is useless for purposes of production, but contains the mound builder, known as the 'lowan', and is a feeding-ground for birds. The Park is situated in the most arid part of the State with a capricious rainfall of 9 in. and great evaporation. In spite of this dryness it is well stocked with birds of the cockatoo and parrot family, also lowans and emus. It also contains a number of black-faced kangaroo. There is at present only one well in the area, and exactly where these animals get the necessary water is not known. The trough at the well is used by some of the birds and by bees, but so far the kangaroos have not been seen to use it. A somewhat similar problem of water supply can be seen in the Egyptian Desert bordering on the Mediterranean which, whereas it is lifeless in the day-time, is stocked with jerboas and various reptiles at night. 